\title{
Composição Corporal e Exigências Líquidas de Macroelementos Inorgânicos (Ca, P, Mg e K) para Ganho de Peso de Bezerros Machos de Origem Leiteira do Nascimento aos 110 Dias de Idade 1
}

\author{
Paulo Afonso Carvalho ${ }^{2}$, Luis Maria Bonnecarrère Sanchez ${ }^{3}$, Cleber Cassol Pires ${ }^{3}$, \\ Julio Viégas ${ }^{3}$, João Pedro Velho ${ }^{4}$, Wagner Paris ${ }^{5}$
}

\begin{abstract}
RESUMO - O presente estudo foi conduzido para avaliar as mudanças na composição corporal e estudar as exigências líquidas de matéria mineral total (MM), cálcio (Ca), fósforo (P), magnésio (Mg) e potássio (K) para ganho de peso de corpo vazio (GPCVZ) e ganho de peso vivo (GPV) de bezerros do nascimento até os 110 dias de idade. Foram usados 18 bezerros da raça Holandês, machos, não castrados, pesando entre 30 e $100 \mathrm{~kg}$. Seis animais foram abatidos ao nascimento, seis aos 50 dias e seis aos 110 dias de idade. Foram ajustadas equações de regressão do logaritmo da quantidade de MM, Ca, P, Mg e K retidos no corpo, em função do logaritmo do peso de corpo vazio (PCVZ). As exigências líquidas dos macroelementos para ganho de peso foram obtidas por derivação das equações de predição da composição corporal. Ocorreu acréscimo na concentração de todos macroelementos no PCVZ e no GPCVZ do nascimento aos 110 dias de vida, entretanto, as exigências destes elementos para GPV decresceram neste mesmo período. As exigências líquidas para 1 kg de GPCVZ, para o intervalo de PCVZ de 27,57 a 74,27 kg, variaram de 69,76 a 74,33 g para MM; 24,24 a 24,67 g para o Ca; 14,64 a 16,06 g para o P; 0,48 a 0,53 g para o Mg e de 3,18 a 3,61 g para o K. As exigências líquidas para $1 \mathrm{~kg}$ de GPV, para o intervalo de PV de 30 a $100 \mathrm{~kg}$, variaram de 63,37 a 55,20 g para MM; 22,02 a 18,32 g para o Ca; 13,30 a 11,93 g para o P; 0,44 a 0,39 g para o Mg e de 2,89 a 2,68 g para o $\mathrm{K}$.
\end{abstract}

Palavras-chave: macrominerais, peso corporal vazio, peso vivo, requisitos nutricionais

\section{Body Composition and Net Inorganic Macroelements (Ca, P, Mg and K) Requirements for Weight Gain of Dairy Male Calves at Newly Born to 110 Days of Age}

ABSTRACT - The work was carried out to evaluate changes in body composition and study the net requirements of mineral matter (MM), calcium (Ca), phosphorus (P), magnesium (Mg) and potassium (K) for empty body weight gain (EBWG) and live weight gain (LWG) of calves from birth to 110 days of age. Eighteen Holstein bull calves with initial average live weight of $40.84 \mathrm{~kg}$ and final of $87.03 \mathrm{~kg}$ were used. Six animals were slaughtered at birth and six at 50 and six at 110 days of age. Regression analysis of the logarithm of the amount of MM, Ca, P, Mg and K body retained in function of the logarithm of empty body weight (EBW) were fitted. The net requirements of macroelements for weight gain were obtained by derivation of the prediction equations of corporal composition. The EBW and EBWG all elements content increased at newly born to 110 days of age, however the LWG elements requirements decreased in same period. The net requirements for $1 \mathrm{~kg}$ EBWG, when EBW ranged from 27.57 to $74.27 \mathrm{~kg}$ was ranged from 69.76 to $74.33 \mathrm{~g}$ for MM; 24.24 to $24.67 \mathrm{~g}$ for Ca; 14.64 to $16.06 \mathrm{~g}$ for P; 0.48 to $0.53 \mathrm{~g}$ for $\mathrm{Mg}$ and 3.18 to $3.61 \mathrm{~g}$ for $\mathrm{K}$. The net requirements for $1 \mathrm{~kg} \mathrm{LWG}$ when LW changes from 30 to $100 \mathrm{~kg}$ was changed from 63.37 to $55.20 \mathrm{~g}$ for MM; 22.02 to $18.32 \mathrm{~g}$ for Ca; 13.30 to $11.93 \mathrm{~g}$ for P; 0.44 to $0.39 \mathrm{~g}$ for $\mathrm{Mg}$ and 2.89 to $2.68 \mathrm{~g}$ for $\mathrm{K}$.

Key Words: empty body weight, live weight, macrominerals, nutritional requirements

\section{Introdução}

A produção de proteína de origem animal exerce importante papel no desenvolvimento e manutenção das populações nos grandes centros urbanos. No entanto, para que a atividade pecuária sobreviva de maneira eficiente, é necessário que sejam atendidos, adequadamente, os requerimentos nutricionais dos animais envolvidos nos sistemas de produção estabelecidos.

De acordo com Possenti et al. (1992), o balanceamento correto de uma dieta animal deve contemplar na sua constituição minerais na forma,

\footnotetext{
${ }^{1}$ Parte da Dissertação apresentada à Universidade Federal de Santa Maria (UFSM), pelo primeiro autor como um dos requisitos para obtenção do Título de Mestre em Zootecnia.

2 Zootecnista, M.Sc. Doutorando pela Universidade Federal de Lavras (UFLA). Bolsista CNPq. Rua Progresso, 41/801. Lavras, MG. 37200.000. Autor para correspondência. E.mail: pac@ufla.br

3 Professor do Departamento de Zootecnia da UFSM, RS.

${ }^{4}$ Acadêmico de Zootecnia (UFSM) - Bolsista de Iniciação Científica CNPq.

5 Zootecnista, Mestrando em Zootecnia pela Universidade Estadual de Maringá (UEM), PR.
} 
quantidade e proporção adequada para que desordens bioquímicas e estruturais não ocorram e funções fisiológicas não se alterem. Os minerais exercem funções relacionadas direta ou indiretamente com o crescimento animal. Dessa forma, é importante que estes recebam o aporte necessário de minerais, durante o seu ciclo de vida (Ferreira et al., 1999).

Conforme descreve Véras (2000), embora representem uma pequena proporção do peso corporal dos animais, os minerais exercem funções vitais no organismo, com reflexos no desempenho animal. Dayrell (1993) destaca que os elementos minerais são essenciais ao metabolismo orgânico, atuando no corpo animal como constituinte das estruturas esqueléticas, regulação e manutenção do estado coloidal da matéria orgânica, regulação do equilíbrio ácido-base e componente ou ativador enzimático e de outras unidades ou sistemas biológicos.

Grande parte dos estudos de deficiências minerais em campo é relacionada à deficiência clínica, quando os animais já apresentam sintomas típicos de deficiência de um ou mais minerais. Entretanto, a deficiência marginal é economicamente mais prejudicial, pois dada a falta de sinais clínicos, nenhum cuidado em especial é tomado, para aumentar o potencial de produtividade animal (Possenti et al., 1993).

O mineral mais abundante no organismo é o cálcio (Ca), sendo que cerca de $98 \%$ do Ca corporal se encontra nos ossos e dentes e o restante, distribuído nos fluidos extracelulares e tecidos moles, estando ausente na gordura (NRC, 1996). Segundo Fischer et al. (1972), os níveis plasmáticos de Ca são estáveis e controlados por mecanismos homeostáticos, variando de 9,0 a $12,0 \mathrm{mg} / 100 \mathrm{~mL}$.

A distribuição do fósforo (P) no corpo animal contempla aproximadamente $80 \%$ desse mineral no esqueleto, e esta fração está intimamente associada com o Ca presente no osso, na forma de hidroxiapatita (Coelho da Silva, 1995). O P também atua no crescimento e diferenciação celular, como componente do DNA e RNA, assim como na utilização e transformação de energia na forma de ATP, ADP e AMP, sendo requerido pelos microorganismos ruminais (NRC, 1996). Os níveis plasmáticos de $P$, em ruminantes, podem variar de 3,0 a 9,0 mg/100 mL, sendo os maiores níveis observados em animais jovens (Underwood, 1966).

O magnésio ( $\mathrm{Mg}$ ) é um elemento também abundante no corpo do animal, estando cerca de $70 \%$ do Mg corporal localizado nos ossos. Aproximadamen- te, um terço do Mg ósseo está ligado ao fosfato e o restante adsorvido frouxamente à superfície da estrutura mineral (Ammerman \& Goodrich, 1983). De acordo com dados apresentados por Church (1993), os níveis séricos de $\mathrm{Mg}$ para ruminantes estão em torno de 2,5 a 3,0 mg/100 mL.

A distribuição do potássio (K) no corpo é bastante diferente do $\mathrm{Ca}, \mathrm{P}$ e Mg. O K está presente nos ossos em quantidades mínimas que corresponde a menos de $50 \mathrm{mg} / \mathrm{kg}$, enquanto os músculos contêm cerca de $4 \mathrm{~g} / \mathrm{kg}$, os tecidos nervosos e secretores 3,5 $\mathrm{g} / \mathrm{kg}$ e o soro e fluidos $200 \mathrm{mg} / \mathrm{kg}$ (Coelho da Silva, 1995).

A concentração corporal de macrominerais é reflexo, principalmente, da proporção de ossos e gordura da carcaça. Fatores como, a idade, raça, grupo genético, sexo, manejo alimentar e condições climáticas aos quais o animal encontra-se submetido, irão afetar a concentração mineral (Maynard et al., 1984).

Com o aumento do teor de gordura corporal, geralmente, deve haver queda nas concentrações dos elementos inorgânicos, pois os depósitos de gordura virtualmente não contêm Ca, e sim quantidades mínimas de P (Signoretti et al., 1999).

Animais muito jovens apresentam na sua constituição corporal uma alta proporção de água, proteínas e minerais e reduzida de lipídios totais (Lucci, 1989), sendo que as concentrações de proteína, minerais e água decrescem com a idade e com a engorda (Berg \& Butterfield, 1976). Entretanto, deve ser considerada a existência de uma maior proporção de ossos, intermediária de músculos e baixa de gordura nos animais muito jovens, em crescimento (Di Marco, 1994). O acúmulo de gordura em bezerros, principalmente machos de origem leiteira, somente inicia após determinado tempo.

Os requerimentos líquidos de minerais para ganho de peso podem ser determinados segundo o método do ARC (1980), pela quantidade total de mineral retida no corpo do animal em determinado ganho de peso. Na mesma linha de pensamento, Araújo et al. (1998) afirmam que para se determinarem as exigências líquidas para crescimento, há necessidade de avaliar a deposição do nutriente no corpo do animal, quando esse apresenta certo incremento em seu peso, implicando em avaliar o conteúdo corporal com diferentes idades e pesos. Esta avaliação é feita com o abate do animal e análise química nos tecidos corporais.

Esses conhecimentos são necessários ao desen- 
volvimento de sistemas de produção que permitam explorar economicamente os animais. Tais particularidades procedem, devendo ser consideradas, quando idealizados e realizados estudos de determinação de composição corporal e estabelecimento de exigências nutricionais, uma vez que deles dependem a precisão e confiabilidade dos resultados obtidos.

Coelho da Silva (1995) descreve que, com o objetivo de se obter um produto animal de melhor qualidade para o consumo humano e de se maximizar a produtividade, as tabelas de exigências estão rapidamente passando da fase de guias ou orientações aproximadas para recomendações cada vez mais rígidas e precisas.

O balanceamento de rações e de suplementos para determinados níveis de desempenho, assim como a estimativa do desempenho a partir de dietas balanceadas requer o conhecimento das exigências nutricionais para as diferentes categorias animais, funções e níveis de desempenho (Boin, 1995).

\section{Material e Métodos}

O presente estudo foi conduzido no Setor de Nutrição Animal do Departamento de Zootecnia da Universidade Federal de Santa Maria (UFSM) no período compreendido entre outubro de 1999 e março de 2001. Foram utilizados 18 bezerros da raça Holandês preto e branco, machos, não castrados, pesando entre 30 e $100 \mathrm{~kg}$. Foram abatidos seis animais ao nascimento, seis aos 50 dias e seis aos 110 dias de vida. Os animais sorteados para os grupos de abate aos 50 e 110 dias foram separados de suas mães e confinados em baias individuais até o dia preestabelecido do sacrifício. Durante este período receberam uma alimentação sólida à vontade e láctea controlada (consumo máximo de $4 \mathrm{~L} / \mathrm{animal} / \mathrm{dia}$ ). No início da segunda semana foi introduzido um concentrado com 18 \% de PB. Também foi ofertado água e feno de alfafa (Medicago sativa) picado, a partir do início da segunda e terceira semana, respectivamente. O desaleitamento dos bezerros ocorreu gradativamente dos 28 aos 50 dias de vida.

À medida que os animais foram atingindo as idades predeterminadas de 50 e 110 dias, foram sendo abatidos. Na ocasião foram pesados e amostrados todos os constituintes corporais separadamente. O peso corporal vazio (PCVZ) foi obtido diretamente pelo somatório dos pesos dos constituintes corporais (patas, cabeça, couro, sangue, órgãos internos, vísceras vazias, gordura interna e carcaça).

As carcaças foram resfriadas em câmara frigorífica a $2^{\circ} \mathrm{C}$ por um período de 24 horas. Decorrido esse período, foi procedida a separação física total de osso, músculo e gordura em todas as $1 / 2$ carcaças esquerdas, assim como, nas patas e cabeça. Após, os diferentes tecidos foram triturados separadamente. Nesse momento foi obtida uma amostra de osso e outra de tecido mole (músculo+gordura) representativo da carcaça inteira + patas e cabeça para cada animal experimental.

As amostras corporais de couro, vísceras + gordura interna, tecido mole da carcaça inteira e osso da carcaça inteira foram pré-desengorduradas com éter de petróleo, conforme metodologia descrita por Kock \& Preston (1979). Após a determinação do teor de umidade e do pré-desengorduramento, as amostras foram moídas finamente em um moinho do tipo Wiley, com peneira de $1 \mathrm{~mm}$ e armazenadas em vidros para posteriores análises químicas bromatológicas, realizadas segundo a metodologia de Silva (1990).

A solução mineral para análise dos macroelementos minerais na matéria seca prédesengordurada dos tecidos constituintes do corpo dos animais foi preparada por via úmida. Após a digestão nitro-perclórica para obtenção da solução mineral, foram feitas as devidas diluições para determinação do Ca, P, Mg e K.

O Ca e o Mg foram determinados por espectrofotometria de absorção atômica, o $\mathrm{P}$ por colorimetria e o K por espectrofotometria de chama, a MM foi considerada como as cinzas, obtidas por calcinação da matéria orgânica dos tecidos, em forno mufla a $550 \stackrel{\circ}{\circ}$ por um período de seis horas.

Os conteúdos corporais de macroelementos inorgânicos foram determinados em função de suas concentrações nos tecidos de constituição do corpo vazio dos animais.

Para predição do conteúdo de MM, Ca, P, Mg e K retido no corpo dos animais experimentais, foi adotada a equação de regressão do logaritmo do conteúdo corporal desses macroelementos inorgânicos, em função do logaritmo do peso de corpo vazio (PCVZ), de acordo com o modelo adotado pelo ARC (1980):

$$
y_{i j}=a+b \cdot X_{i j}+e_{i j} \text {, }
$$

em que: $y_{\mathrm{ij}}=$ logaritmo de base 10 da quantidade do componente no corpo vazio; a = intercepto; $\mathrm{b}$ = coeficiente de regressão do logaritmo do conteúdo MM, Ca, P, Mg e K, em função do logaritmo do peso de corpo vazio; $\mathrm{X}_{\mathrm{ij}}=$ logaritmo do peso de corpo 
vazio; $\mathrm{e}_{\mathrm{Ij}}=$ erro aleatório.

Para conversão do peso vivo em peso de corpo vazio, utilizou-se a equação obtida por regressão do peso de corpo vazio dos 18 animais abatidos, em função do peso vivo ao abate dos mesmos, a faixa de peso vivo variou entre 30 e $100 \mathrm{~kg}$ com correspondentes pesos de corpo vazio variando de 27,57 a 74,27 kg.

Foi determinado um fator de conversão (FC) do PV em PCVZ para animais de diferentes pesos vivo, obtido pelo quociente do PV em função do PCVZ dos bezerros, e este FC foi utilizado para converter GPCVZ em GPV. Tal FC permite a conversão de peso corporal para peso vivo, por considerar o incremento na quantidade de conteúdo gastrintestinal, urina e suco biliar presentes junto ao organismo, em diferentes fases da vida dos animais.

Derivando-se as equações logarítmicas de estimativa do conteúdo corporal de MM, Ca, P, Mg e K, foram obtidas as equações de predição das exigências líquidas desses macroelementos inorgânicos para ganho de $1 \mathrm{~kg}$ de PCVZ, do tipo:

$$
\mathrm{y}^{\prime}=\mathrm{b} \cdot 10^{\mathrm{a}} \cdot \mathrm{X}^{(\mathrm{b}-1)},
$$

em que: y’ = Exigência líquida de MM, Ca, P, Mg e K para 1 kg de GPCVZ; b = Coeficiente de regressão do logaritmo do conteúdo de MM total, Ca, P, Mg e K em função do logaritmo de PCVZ; a = Intercepto; $\mathrm{X}=$ PCVZ $(\mathrm{kg})$.

As exigências líquidas de MM, Ca, P, Mg e K para GPV foram obtidas dividindo-se os requerimentos GPCVZ pelo FC, obtido para cada peso, no presente estudo.

Os dados foram submetidos a análises de regressão para o estudo das variáveis, por intermédio do programa SAS (1996).

\section{Resultados e Discussão}

Na Tabela 1, são apresentados os parâmetros das equações de regressão do logaritmo da quantidade de $\mathrm{MM}, \mathrm{Ca}, \mathrm{Mg}, \mathrm{P}$ e $\mathrm{K}$ presente no corpo vazio dos bezerros, em função do logaritmo do peso de corpo vazio desde o nascimento até os 110 dias de vida.

Para todos os minerais analisados houve efeito altamente significativo da regressão $(\mathrm{P}<0,01)$, com coeficientes de determinação $\left(\mathrm{r}^{2}\right)$ bastante elevados, indicando bom ajuste das equações obtidas. A equação logarítmica do conteúdo corporal de $\mathrm{K}$ apresentou melhor ajuste do que as demais, cujos valores obtidos podem ser considerados satisfatórios. Vale ressaltar que esses animais foram desaleitados precocemente a partir dos 28 dias de vida, fato este que, possivelmente, pode ter afetado o perfeito desenvolvimento de alguns indivíduos nessa fase de vida, os quais apresentaram uma proporção de ossos bastante alta em relação aos outros tecidos de constituição da carcaça.

Os $r^{2}$ obtidos nesse estudo são superiores aos encontrados por Véras (2000), a qual encontrou $\mathrm{r}^{2}$ de $21 \%$ para Ca, $61 \%$ para $\mathrm{P}, 13 \%$ para $\mathrm{Mg}$ e $79 \%$ para $\mathrm{K}$ nas equações ajustadas para bovinos Nelore na faixa de peso de 300 a $450 \mathrm{~kg}$ de PV. Já Fontes (1995) obteve $\mathrm{r}^{2}$ de $74 \%$ para Ca, $52 \%$ para $\mathrm{P}, 50 \%$ para $\mathrm{Mg}$ e $70 \%$ para $\mathrm{K}$ nas equações ajustadas para bovinos Nelore (castrados ou não) de 200 a 450 kg de PCVZ. Ambos os autores justificam os baixos valores encontrados para os $\mathrm{r}^{2}$ devidos, provavelmente, ao fato dos animais utilizados estarem saindo da fase de crescimento e, portanto, apresentarem menor concentração de minerais no corpo vazio.

Derivando-se as equações logarítmicas de regressão, foram obtidas as equações (Tabela 2) que permitem a estimativa da exigência líquida de ganho ou conteúdo de MM, Ca, P e K no ganho de 1 kg de peso corporal vazio, para animais de diferentes PCVZ,

Tabela 1 - Parâmetros das equações de regressão do logaritmo dos conteúdos de matéria mineral $(\mathrm{MM})$, cálcio $(\mathrm{Ca})$, magnésio $(\mathrm{Mg})$, fósforo $(\mathrm{P})$ e potássio $(K)$ no corpo vazio, em função do logaritmo do peso do corpo vazio $(\mathrm{kg})$ de bezerros holandeses do nascimento aos 110 dias de idade

Table 1 - Parameters of the regression equations of mineral matter (MM), calcium (Ca), phosphorus $(P)$, magnesium $(\mathrm{Mg})$ and potassium $(K)$ logarithm content in the empty body in according to the empty body weight logarithm $(\mathrm{kg})$ of dairy calves at newly born to 110 days of age

\begin{tabular}{lcc}
\hline $\begin{array}{l}\text { Nutriente } \\
\text { Nutrient }\end{array}$ & $\begin{array}{c}\text { Parâmetros } \\
\text { Parameter }\end{array}$ & $\mathrm{r}^{2}(\%)$ \\
\cline { 2 - 2 } &
\end{tabular}

\begin{tabular}{lccl}
\cline { 2 - 3 } & $\begin{array}{c}\text { Intercepto (a) } \\
\text { Intercept }\end{array}$ & $\begin{array}{c}\text { Coeficiente(b) } \\
\text { Coefficient }\end{array}$ & \\
\hline $\begin{array}{l}\text { Matéria mineral } \\
\text { Mineral matter }\end{array}$ & $-1,273801$ & 1,063254 & $90,58^{* *}$ \\
$\begin{array}{l}\text { Cálcio } \\
\text { Calcium }\end{array}$ & $-1,647862$ & 1,017373 & $79,85^{* *}$ \\
$\begin{array}{l}\text { Fósforo } \\
\text { Phosphorus }\end{array}$ & $-2,005394$ & 1,092392 & $89,50^{* *}$ \\
$\begin{array}{l}\text { Magnésio } \\
\text { Magnesium }\end{array}$ & $-3,505290$ & 1,100879 & $84,16^{* *}$ \\
$\begin{array}{l}\text { Potássio } \\
\text { Potassium }\end{array}$ & $-2,730274$ & 1,126226 & $96,58^{* *}$ \\
\hline
\end{tabular}

** $(P<0,01)$. 
dentro do intervalo de peso adotado.

Consta na Tabela 3 o conteúdo corporal de MM e dos macroelementos $\mathrm{Ca}, \mathrm{Mg}, \mathrm{P}$ e $\mathrm{K}$ em g/kg de PCVZ, bem como as quantidades desses nutrientes em g/kg no ganho de peso corporal vazio (GPCVZ), obtidos para o intervalo de PCVZ de 27,57 a 74,27 kg, a partir das equações mostradas nas Tabelas 1 e 2 .

Observou-se acréscimo na ordem de 6,08\% na composição de MM, de 1,69\% de Ca, de 8,71\% de P, de $10,42 \%$ de $\mathrm{Mg}$ e de $11,83 \%$ de $\mathrm{K}$ retido no corpo vazio dos bezerros, quando o PCVZ passou de 27,57 para 74,27 kg. Destaca-se que os animais em questão eram bezerros na fase inicial da vida produtiva, do nascimento aos 110 dias de vida, enquadrando-se na fase mais intensa de crescimento pós-natal.

Foi verificado no presente experimento que, apesar de a proporção de ossos na carcaça diminuir em relação à proporção de músculo e gordura, observou-se que a quantidade absoluta de ossos aumentou. Os valores observados foram 9,4; 12,0 e 14,6 kg de osso na carcaça ao nascimento, 50 e 110 dias de vida, respectivamente. Tal fato indica crescimento do tecido ósseo do nascimento até os 110 dias de vida, justificando o incremento na retenção de macrominerais na composição do corpo vazio.

Tabela 2 - Equações de predição das exigências líquidas de matéria mineral, cálcio, fósforo, magnésio e potássio em $\mathrm{g} / \mathrm{kg}$ de ganho de peso de corpo vazio (GPCVZ), em função do peso de corpo vazio (PCVZ) em kg

Table 2 - Prediction equations of mineral matter, calcium, phosphorus, magnesium and potassium net requirement for $\mathrm{g} / \mathrm{kg}$ of empty body weight gain (EBWG), according to the empty body weight $(E B W)$ in $\mathrm{kg}$

\begin{tabular}{|c|c|}
\hline $\begin{array}{l}\text { Nutriente } \\
\text { Nutrient }\end{array}$ & $\begin{array}{l}\text { Equações } \\
\text { Equations }\end{array}$ \\
\hline Matéria mineral & $Y=1,063254.10^{-1,273801}$ \\
\hline Mineral matter & $\begin{array}{l}\text { PCVZ 0,063254 } \\
E B W\end{array}$ \\
\hline Cálcio & $\mathrm{Y}=1,017373.10^{-1,647862}$ \\
\hline Calcium & $\begin{array}{l}\text { PCVZ 0,017373 } \\
\text { EBW }\end{array}$ \\
\hline Fósforo & $Y=1,092392 \cdot 10^{-2,005394}$ \\
\hline Phosphorus & $\begin{array}{l}\text { PCVZ 0,092392 } \\
E B W\end{array}$ \\
\hline Magnésio & $Y=1,100879 \cdot 10^{-3,505290}$ \\
\hline Magnesium & $\begin{array}{l}\text { PCVZ 0,100879 } \\
E B W\end{array}$ \\
\hline $\begin{array}{l}\text { Potássio } \\
\text { Potassium }\end{array}$ & $\begin{array}{l}Y=1,126225 \cdot 10^{-2,730274} \\
P C V Z 0,126225 \\
E B W\end{array}$ \\
\hline
\end{tabular}

A composição do ganho de peso corporal sofreu incremento no conteúdo de MM total, à medida que se elevou o PCVZ, variando de 69,76 a 74,33 g/kg GPCVZ, quando o PCVZ variou de 27,57 a 74,27 kg. O mesmo comportamento foi observado para os demais macrominerais. O aumento aparente no conteúdo desses minerais no GPCVZ, com a elevação do PCVZ pode ser explicado, em parte, pela alta proporção de ossos na carcaça dos bezerros, 25,47 \% aos 110 dias de vida. Este valor para proporção de ossos na carcaça é bastante superior ao verificado em animais mais velhos ou adultos, como demonstrado por Moletta \& Perotto (1997), que encontraram 14,81\% de osso na carcaça de animais pesando $460 \mathrm{~kg}$, e por Peron et al. (1995), que obtiveram $14,21 \%$ de osso na carcaça de animais abatidos com $450 \mathrm{~kg}$ de PV. De acordo com Martin (1993), as maiores proporções de elementos inorgânicos se encontram nos ossos, principalmente com relação ao Ca, $\mathrm{P}$ e Mg corporal, ficando os demais tecidos com porcentagens bem menores.

Araújo et al. (1998) trabalhando com bezerros mestiços (Holandês x zebú), submetidos a dietas com níveis crescentes de volumoso (10, 20, 40, 55 e 90 \%), dentro da faixa de 42,94 a 275,41 kg de PCVZ, obtiveram valores crescentes (g/kg GPCVZ) para as exigências líquidas de cálcio (todos os níveis de volumoso), fósforo (25, 40, 55 e 90\%) e magnésio (10, 25, 40 e 90\%), à medida que se elevou o PCVZ. Da mesma forma, Signoretti et al. (1999) encontraram valores crescentes para as exigências líquidas de GPCVZ, à medida que elevou-se o PCVZ de bezerros Holandês. Os valores apresentados por estes autores variaram, dentro dos diferentes níveis de volumoso, de 12,77 a 29,08 g de Ca, de 9,54 a 16,60 g de $\mathrm{P}$ e de 0,32 a 0,51 g de $\mathrm{Mg}$ para ganho de $1 \mathrm{~kg}$ de corpo vazio, quando o PCVZ aumentou de 62,78 a $260,70 \mathrm{~kg}$, reaspectivamente. Tanto Araújo et al. (1998) como Signoretti et al. (1999) atribuem os acréscimos nas exigências líquidas dos macroelementos com o aumento do PCVZ, a uma elevada taxa de crescimento e alta proporção de ossos na carcaça dos animais muito jovens. Fato este, que concorda com os resultados aqui obtidos.

Os animais jovens absorvem Ca mais eficientemente que os adultos, entretanto, os requerimentos são maiores para os animais mais jovens, uma vez que as taxas de crescimento ósseo e de ganho de peso são mais elevadas (NRC, 1984).

Fontes (1995) apresentou conteúdos corporais de 21,69 g de Ca, 12,86 g de P, 0,55 g de Mg e 1,90 g de 
Tabela 3 - Conteúdo de matéria mineral (MM), cálcio $(\mathrm{Ca})$, fósforo $(\mathrm{P})$, magnésio $(\mathrm{Mg})$ e potássio $(\mathrm{K})$ em g/kg de peso corporal vazio (PCVZ) e exigência líquida de matéria mineral $(\mathrm{MM})$, cálcio (Ca), fósforo $(P)$, magnésio (Mg) e potássio (K) em $\mathrm{g} / \mathrm{kg}$ de ganho de peso de corpo vazio (GPCVZ) de bezerros machos Holandês, do nascimento aos 110 dias de idade

Table 3 - Mineral matter (MM), calcium (Ca), phosphorus ( $P$ ), magnesium (Mg) and potassium $(K)$ content in g/kg the empty body weight (EBW) and net requirement of mineral matter (MM), calcium (Ca), phosphorus ( $P$ ), magnesium (Mg) and potassium $(K))$ in $\mathrm{g} / \mathrm{kg}$ the empty body weight gain (EBWG) of dairy male calves at newly born to 110 days of age

\begin{tabular}{|c|c|c|c|c|c|c|c|c|c|c|c|}
\hline \multirow[t]{3}{*}{$\begin{array}{l}\mathrm{PV} \\
L W\end{array}$} & \multirow[t]{3}{*}{$\begin{array}{c}\text { PCVZ } \\
E B W\end{array}$} & \multicolumn{10}{|c|}{$\begin{array}{l}\text { Nutriente } \\
\text { Nutrient }\end{array}$} \\
\hline & & \multicolumn{2}{|c|}{ MM } & \multicolumn{2}{|c|}{$\mathrm{Ca}$} & \multicolumn{2}{|c|}{$\mathrm{P}$} & \multicolumn{2}{|c|}{ Mg } & \multicolumn{2}{|c|}{ K } \\
\hline & & $\begin{array}{c}\mathrm{g} / \mathrm{kg} \\
\mathrm{PCVZ} \\
E B W\end{array}$ & $\begin{array}{c}\mathrm{g} / \mathrm{kg} \\
\mathrm{GPCVZ} \\
E B W G\end{array}$ & $\begin{array}{c}\mathrm{g} / \mathrm{kg} \\
\mathrm{PCVZ} \\
E B W\end{array}$ & $\begin{array}{c}\mathrm{g} / \mathrm{kg} \\
\text { GPCVZ } \\
E B W G\end{array}$ & $\begin{array}{c}\mathrm{g} / \mathrm{kg} \\
\mathrm{PCVZ} \\
E B W\end{array}$ & $\begin{array}{c}\mathrm{g} / \mathrm{kg} \\
\mathrm{GPCVZ} \\
E B W G\end{array}$ & $\begin{array}{c}\mathrm{g} / \mathrm{kg} \\
\mathrm{PCVZ} \\
E B W\end{array}$ & $\begin{array}{c}\mathrm{g} / \mathrm{kg} \\
\mathrm{GPCVZ} \\
E B W G\end{array}$ & $\begin{array}{c}\mathrm{g} / \mathrm{kg} \\
\mathrm{PCVZ} \\
E B W\end{array}$ & $\begin{array}{c}\mathrm{g} / \mathrm{kg} \\
\mathrm{GPCVZ} \\
E B W G\end{array}$ \\
\hline 30 & 27,57 & 65,66 & 69,76 & 23,83 & 24,24 & 13,42 & 14,64 & 0,43 & 0,48 & 2,83 & 3,18 \\
\hline 40 & 34,24 & 66,57 & 70,78 & 23,92 & 24,34 & 13,69 & 14,95 & 0,44 & 0,49 & 2,91 & 3,27 \\
\hline 50 & 40,91 & 67,32 & 71,58 & 24,00 & 24,41 & 13,92 & 15,20 & 0,45 & 0,50 & 2,97 & 3,35 \\
\hline 60 & 47,58 & 67,97 & 72,27 & 24,06 & 24,48 & 14,11 & 15,42 & 0,46 & 0,51 & 3,03 & 3,41 \\
\hline 70 & 54,26 & 68,53 & 72,87 & 24,11 & 24,53 & 14,28 & 15,60 & 0,46 & 0,51 & 3,08 & 3,47 \\
\hline 80 & 60,93 & 69,04 & 73,41 & 24,16 & 24,58 & 14,44 & 15,77 & 0,47 & 0,52 & 3,13 & 3,52 \\
\hline 90 & 67,60 & 69,49 & 73,89 & 24,21 & 24,63 & 14,58 & 15,92 & 0,48 & 0,53 & 3,17 & 3,57 \\
\hline 100 & 74,27 & 69,91 & 74,33 & 24,25 & 24,67 & 14,70 & 16,06 & 0,48 & 0,53 & 3,21 & 3,61 \\
\hline
\end{tabular}

$\mathrm{K} / \mathrm{kg}$ de PCVZ e exigências liquidas de 15,11 g de Ca, 8,93 g de $\mathrm{P}, 0,43 \mathrm{~g}$ de $\mathrm{Mg}$ e 1,82 g de K para $1 \mathrm{~kg}$ de GPCVZ de bovinos com $200 \mathrm{~kg}$ de PCVZ, enquadrados em uma faixa de PCVZ variando de 200 a $450 \mathrm{~kg}$. Já Véras (2000) apresentou exigências de 9,60 g de $\mathrm{Ca}, 7,90$ g de $\mathrm{P}, 0,25$ g de $\mathrm{Mg}$ e 2,66 g de K, para $1 \mathrm{~kg}$ de GPCVZ de bovinos Nelore com 251,07 kg de PCVZ, enquadrados em uma faixa de PCVZ alcançando até $399,73 \mathrm{~kg}$.

Os valores das exigências liquidas para GPCVZ obtidas por Fontes (1995) e Véras (2000), são inferiores às determinadas neste experimento. Os referidos autores trabalharam com animais que além de apresentarem pesos corporais mais elevados, faziam parte de uma faixa de peso, adotada para o ajuste das equações logaritmas, que atingia até a maturidade. Portanto, apresentavam diferentes composições corporais. O limite superior da faixa de peso analisada no presente experimento $(74,27 \mathrm{~kg})$ é menor que o limite inferior da faixa de peso adotada pelos experimentos realizados, inferindo diferenças na composição corporal. Animais mais desenvolvidos ou adultos apresentam menores proporções de osso e maiores de tecido adiposo, o que reflete em uma menor composição proporcional de minerais no corpo desses animais. Tais constatações, indicam que em um primeiro estágio de vida os animais necessitam de quantidades crescentes de minerais para o desenvolvimento estrutural do corpo. Depois, com a aproximação da maturidade, os animais iniciam a acumular gordura, fase em que as necessidades de minerais para o desenvolvimento passam a ser descrescentes.

$\mathrm{Na}$ Tabela 4, encontram-se os resultados referentes às exigências líquidas de minerais totais (MM), $\mathrm{Ca}, \mathrm{Mg}, \mathrm{P}$ e K em g/kg de ganho de peso vivo (GPV), para o intervalo de PV de 30 a 100 kg. As exigências liquidas para GPV foram obtidas dividindo-se as respectivas exigências de GPCVZ pelo fator de correção (FC) obtido no presente experimento (PV/ PCVZ), cujo valor médio foi 1,25. Observou-se que, à medida que se elevou o PV a relação PV/PCVZ também se elevou, fato atribuído ao enchimento do trato gastrintestinal com a elevação do PV.

Os requerimentos líquidos de macrominerais para GPV decresceram com o aumento do PV. Os valores reduziram em 12,89\% para $\mathrm{MM}, 16,80 \%$ para Ca, $10,30 \%$ para $\mathrm{P}, 11,36 \%$ para $\mathrm{Mg}$ e em $7,27 \%$ para $\mathrm{K}$, quando o PV se elevou de 30 para $100 \mathrm{~kg}$. O decréscimo dos requerimentos líquidos para GPV, com a elevação do PV é justificado pela diluição da composição do mesmo, como referido anteriormente.

O ARC (1980) propôs valores constantes de 14,0 g de $\mathrm{Ca}$ e 8,0 g de $\mathrm{P}$, para satisfazer as exigências liquidas de $1 \mathrm{~kg}$ de ganho, independentemente da idade. Entretanto, o AFRC (1991), considerando o PV à maturidade, relata valores decrescentes para os requerimentos de macrominerais, conforme o aumento da maturidade do animal, com valores de 16,2 e 13,9 g de $\mathrm{Ca} / \mathrm{kg}$ de GPV e de 8,8 e 7,7 g de P/kg de GPV para animais com 100 e $200 \mathrm{~kg}$ de PV, respectivamente. 
Os valores das exigências líquidas para GPV, calculadas pelo sistema NRC (1988) para bezerros da raça Holandês, com 30 kg de PV são de 11,68 g de Ca e 13,01 g de P. Por sua vez, o AFRC (1991) estima valores superiores para Ca (18,64 g) e inferiores para P (9,99 g) para suprir as exigências do mesmo animal. Tais valores, preconizados pelos referidos comitês, são inferiores aos obtidos no presente estudo.

O ARC (1980) sugere uma exigência líquida de 0,45 g Mg/kg de GPCVZ e de 2,0 g K/kg de GPCVZ, valores estes levemente inferiores aos obtido neste estudo, cujo comportamento foi crescente para GPCVZ e decrescente para GPV.

Coelho da Silva (1995), comparando dados brasileiros com os estimados segundo metodologia utilizada pelo sistema ARC/AFRC, concluiu que as exigências líquidas dos animais nacionais, obtidas para $\mathrm{Ca}, \mathrm{P}, \mathrm{Mg}$ e $\mathrm{K}$, foram quase o dobro daquelas propostas pelo AFRC (1991) e ligeiramente superiores às recomendadas pelo ARC (1980).

Desde a última edição do NRC para gado de leite (1988), houve estudos que demonstraram certos problemas associados com a aplicação de campo das recomendações anteriores, sugerindo mudanças nas recomendações para a maioria dos elementos minerais em dietas de animais jovens.

O NRC (2001) sugere que, para animais submetidos a dietas lácteas, as concentrações de $\mathrm{Ca}$ e $\mathrm{P}$ recomendadas devem ser aumentadas de 0,7 a $1,0 \%$

Tabela 4 - Exigência líquida de matéria mineral (MM), cálcio $(\mathrm{Ca})$, magnésio $(\mathrm{Mg})$, fósforo $(\mathrm{P})$ e potássio $(\mathrm{K})$ em $\mathrm{g} / \mathrm{kg}$ de ganho de peso vivo (GPV) de bezerros Holandês, machos inteiros, do nascimento aos 110 dias de vida

Table 4 - Net requirement of mineral matter (MM), calcium $(\mathrm{Ca})$, phosphorus $(P)$, magnesium $(\mathrm{Mg})$ and potassium (K)) in $\mathrm{g} / \mathrm{kg}$ of live weight gain (LWG) of dairy male calves at birth to 110 days of age

\begin{tabular}{lccccc}
\hline PV & \multicolumn{5}{c}{$\begin{array}{c}\text { Nutriente } \\
\text { Nutrient }\end{array}$} \\
\cline { 2 - 6 } & MM & Ca & P & Mg & K \\
\hline \multicolumn{5}{c}{$(\mathrm{g} / \mathrm{kg} \mathrm{GPV})$} \\
\cline { 3 - 6 }$(g / k g ~ L W G)$ \\
30 & 63,37 & 22,02 & 13,30 & 0,44 & 2,89 \\
40 & 60,59 & 20,84 & 12,80 & 0,42 & 2,80 \\
50 & 58,57 & 19,98 & 12,44 & 0,41 & 2,74 \\
60 & 57,31 & 19,41 & 12,23 & 0,40 & 2,71 \\
70 & 56,48 & 19,02 & 12,09 & 0,40 & 2,69 \\
80 & 55,90 & 18,72 & 12,01 & 0,40 & 2,68 \\
90 & 55,50 & 18,50 & 11,96 & 0,39 & 2,68 \\
100 & 55,20 & 18,32 & 11,93 & 0,39 & 2,68 \\
\hline
\end{tabular}

R. Bras. Zootec., v.32, n.6, p.1492-1499, 2003 para Ca e de 0,6 a 0,7 \% para P. Os aumentos nos requerimentos estão associados a um maior nível de gordura observado no leite integral e substitutos lácteos e conseqüente aumento de energia da dieta. De acordo com o comitê, valores de gordura dietéticos mais altos aumentam a perda de Ca nas fezes por causa da formação de sabão entre o Ca e ácidos graxos de cadeia longa no intestino. No entanto, McDowell (1992) alerta que cuidados especiais devem ser tomados quando da alteração do nível dietético de algum elemento mineral específico, ficando atento aos possíveis efeitos de tal mudança no estado de absorção de outros elementos minerais.

As exigências de minerais para bezerros jovens devem basear-se na quantidade e qualidade do alimento consumido, uma vez que animais bem alimentados apresentarão uma maior velocidade de crescimento, alterando rapidamente a constituição corporal e, conseqüentemente, as necessidades nutricionais (NRC, 2001).

Através dos dados apresentados é possível verificar que na literatura existe uma grande variação nos valores dos requerimentos de macroelementos inorgânicos, de acordo com o sistema de criação e animais envolvidos. Portanto, procede a necessidade de se conduzir mais estudos nesta área, principalmente com animais em crescimento, enquadrados em faixas de peso com limites superior não muito elevados, objetivando-se o conhecimento e esclarecimento de questões ainda em aberto.

\section{Conclusões}

Ocorre um acréscimo na concentração de matéria mineral total, cálcio, fósforo, magnésio e potássio no corpo vazio e no ganho de peso de corpo vazio de bezerros machos da raça Holandês, do nascimento até os 110 dias de idade.

As exigências líquidas para ganho de $1 \mathrm{~kg}$ de PV, de bezerros da raça Holandês, variam de 63,37 a 55,20 g para matéria mineral total, de 22,02 a 18,32 g para o cálcio, de 13,30 a 11,93 g para o fósforo, de 0,44 a 0,39 g para o magnésio e de 2,89 a 2,68 g para o potássio, para o intervalo de PV de 30 a $100 \mathrm{~kg}$.

Os valores de composição corporal e requerimentos de macroelementos inorgânicos determinados no presente experimento são maiores que os valores preconizados pelos comitês britânico e americano de exigências nutricionais. 


\section{Literatura Citada}

AGRICULTURAL AND FOOD RESEARCH COUNCIL AFRC. A reaprasisal of the calcium and phosphorus requirements of sheep and cattle. Report 6. Nutrition Abstract and Reviews, v.61, n.9, p.573-612, 1991.

AGRICULTURAL RESEARCH COUNCIL - ARC. The nutrient requeriments of farm livestock. England: Commonwealth Agriculture Bureaux, 1980. 350p.

AMMERMANC, B.; GOODRICH, R.D. Advances in mineral nutrition in ruminants. Journal of Animal Science, n.57, v.1, p.519-533, 1983.

ARAÚJO, G.G.L.; COELHO DA SILVA, J.F.; VALADARES FILHO, S.C. et al. Exigências líquidas de macroelementos minerais de bezerros recebendo dietas com diferentes níveis de volumoso. In: REUNIÃO ANUAL DA SOCIEDADE BRASILEIRA DE ZOOTECNIA, 35., 1998, Botucatu. Anais... Botucatu: Sociedade Brasileira de Zootecnia, 1998. p. 335-337.

BERG, R.T.; BUTTERFIELD, R.M. New concepts of cattle growth. New York: Sydney University, 1976. 240p.

BOIN, C. Alguns dados sobre exigências de energia e de proteína de zebuínos. In: SIMPÓSIO INTERNACIONAL SOBRE EXIGÊNCIAS NUTRICIONAIS DE RUMINANTES, 1995, Viçosa, MG. Anais ... Viçosa: Universidade Federal de Viçosa, 1995. p.457-465.

CHURCH, D.C. El Rumiante: Fisiología digestiva y nutrición. Acríbia, Zaragoza, España, 1993, 641 p.

COELHO DA SILVA, J.F. Exigências de macroelementos inorgânicos para bovinos: O sistema ARC/AFRC e a experiência no Brasil. In: SIMPÓSIO INTERNACIONAL SOBRE EXIGÊNCIAS NUTRICIONAIS DE RUMINANTES, 1995, Viçosa, MG. Anais ... Viçosa: Universidade Federal de Viçosa, 1995. p.467-504.

DAYRELL, M. S. Suplementação mineral para vacas de leite de alta produção. In: MINI-SIMPÓSIO DO COLÉGIO BRASILEIRO DE NUTRIÇÃO ANIMAL / NUTRIÇÃO E ALIMENTAÇÃO DE GADO LEITEIRO, 1993, Campinas. Anais ... Campinas: 1993. p.71-81.

DI MARCO, O.N. Crescimiento y respuesta animal. Balcarce: Associación Argentina de Producción Animal, 1994. 129p.

FERREIRA, M.A.; VALADARES FILHO, S.C.; MUNIZ, E.B. et al. Composição corporal e exigências líquidas de macroelementos minerais de bovinos F1 Simental x Nelore. Revista Brasileira de Zootecnia, v.28, n.2, p.361-367, 1999.

FISCHER, L.J.; LISTER, E.E.; JORDAN, W.A. et al. Effects of plane of nutrition confinement system, and forage preservation on suplemental mineral intake and content of minerals in the blood of pregnant beef cows. Canadian Journal Animal Science, n.52, n.4, p. 693-702, 1972.

FONTES, C.A.A. Composição corporal, exigências líquidas de nutrientes para ganho de peso e desempenho produtivo de animais zebuínos e mestiços europeu-zebú - Resultados experimentais. In: SIMPÓSIO INTERNACIONAL SOBRE EXIGÊNCIAS NUTRICIONAIS DE RUMINANTES, 1995, Viçosa, MG. Anais ... Viçosa: Universidade Federal de Viçosa, 1995. p.419-456.

KOCK, S.W.; PRESTON, R.L. Estimation of bovine carcass composition by the urea diluition techinique. Journal of Animal Science, v.48, n.2, p. 319, 1979.

LUCCI, C.S. Bovinos leiteiros jovens. São Paulo: Nobel, 1989. 371p.

MARTIN, L.C.T. Nutrição mineral de bovinos de corte. 2.ed. São Paulo: Nobel, 1993. 173p.
McDOWELL, L.R. Minerals in animal and human nutrition. San Diego: Academic Press, 1992. 85p.

MAYNARD, L.; LOOSLI, J.; HENTZ, H. et al. Nutrição animal. Rio de Janeiro: Freitas Bastos S. A., 1984. 726p.

MOLETTA, J.L.; PEROTTO, D. Efeito do manejo alimentar no pré e/ou pós-desmame, sobre o desempenho e características de carcaça de novilhos. In: REUNIÃO ANUAL DA SOCIEDADE BRASILEIRA DE ZOOTECNIA, 34,, 1997. Juiz de Fora. Anais ... Juiz de Fora, 1997. p.340-342.

NATIONAL RESEARCH COUNCIL - NRC. Nutrient requeriments of beef cattle. 6.ed. Washington, D.C.: National Academy of Science, 1984. 90p.

NATIONAL RESEARCH COUNCIL - NRC. Nutrient requeriments of dairy cattle. 6.ed. Washington, D.C.: National Academy of Science, 1988. 157p.

NATIONAL RESEARCH COUNCIL - NRC. Nutrient requeriments of beef cattle. 7.ed. Washington, D.C.: National Academy of Science, 1996. 242p.

NATIONAL RESEARCH COUNCIL - NRC. Nutrient requeriments of dairy cattle. 7.ed. Washington, D.C.: National Academy of Science, 2001. 381p.

PERON, A.J.; FONTES, C.A.A.; LANA, R.P. et al. Medidas quantitativas e proporções de músculo, tecido adiposo e ossos da carcaça de novilhos de cinco grupos genéticos, submetidos à alimentação restrita e "ad libitum”. Revista da Sociedade Brasileira de Zootecnia, v.24, n.1, p.126137, 1995.

POSSENTI, R.A.; LOBÃO, A.O.; RIBEIRO, W.R. et al. Determinações minerais em forragens e tecidos de bovinos. Boletim da Indústria Animal, v.49, n.2, p. 131-144, 1992.

POSSENTI, R.A.; RIBEIRO, W.R.; OTSUK, I. P. Determinações minerais em tecidos de bovinos suplementados ou não com minerais. Boletim da Indústria Animal, v.50, n.1, p.43-48, 1993.

STATISTICAL ANALYSIS SYSTEM - SAS. User's guide: Stactistcs. Version 6.11. Cary: 1996.

SIGNORETTI, R. D.; COELHO DA SILVA, J. F.; VALADARES FILHO, S. de C. et al. Composição corporal e exigências líquidas e dietéticas de macroelementos inorgânicos (Ca, P, $\mathrm{Mg}, \mathrm{K}$ e Na) de bezerros da raça holandesa alimentados com dietas contendo diferentes níveis de volumoso. Revista Brasileira de Zootecnia, v.28, n.1, p. 205-213, 1999.

SILVA, D.J. Análise de alimentos: métodos químicos e biológicos. Viçosa, MG: Universidade Federal Viçosa, 1990. 165p.

UNDERWOOD, E.J. The mineral nutrition of livestock. Aberdeen: Central Press, 1966. 237p.

VÉRAS, A.S.C. Consumo, digestibilidade, composição corporal e exigências nutricionais de bovinos nelore alimentados com rações contendo diferentes níveis de concentrado. Viçosa, MG: Universidade Federal de Viçosa, 2000. 166p. Tese (Doutorado em Zootecnia) - Universidade Federal de Viçosa, 2000. 